\title{
A BIBLIOTECA JESUÍTICA "LES FONTAINES": UM PARAÍSO À BEIRA DA FLORESTA
}

Às margens de uma das mais belas e antigas florestas da França, a de Chantilly e a cerca de quarenta quilômetros ao norte de Paris, localiza-se a Bibliothèque des Fontaines ${ }^{1}$. O majestoso conjunto de prédios que abriga cerca de 500.000 livros, pertence a uma das mais importantes ordens religiosas: a Companhia de Jesus. Num primeiro exame, o seu singular estatuto ligado à história de suas coleções deveriam posicioná-la na categoria das bibliotecas especializadas em ciências da Religião e da Filosofia, mas seus atributos ultrapassam, em muito, limites tão redutores.
Comecemos por sua história ${ }^{2}$. Logo que a Companhia de Jesus foi expulsa da França, em 1762, e que o papa Clemente XIV em 1773 decretou sua supressão, as afamadas bibliotecas pertencentes a seminários e colégios jesuíticos foram confiscadas ou dispersadas. Quando do restabelecimento da ordem em 1814, era preciso reconstituir as coleções que haviam servido a tantas gerações e somá-las ao conjunto de aquisições de obras publicadas entre os séculos XVI e XVIII que os jesuítas começavam a acumular. O trabalho de aquisições para a reestruturação da biblioteca foi notável pois metade do acervo é constituído por obras publicadas antes de 1830, e as impressões em língua estrangeira perfazem, elas também, um número expressivo.

2. Emprestarei aqui várias informações extraídas do livro Patrimoine des Bibliothèques de France. Paris, Payot, 1995. 
A instalação dos jesuítas no belo conjunto arquitetônico designado como Les Fontaines, depois da segunda guerra mundial, tinha também outros objetivos. Tratava-se de reagrupar duas casas de formação, instaladas no estrangeiro, quando das leis de expulsão de 1880. Os fundos atuais são originalmente debitários das bibliotecas destas duas casas, somados aos fundos de outros seminários que tinham sido, igualmente, fechados na França. Eis a explicação dos aportes sucessivos que explicam a riqueza e a diversidade das coleções que aí se abrigam.

Inicialmente, em 1951, Les Fontaines acolheu a biblioteca da casa São Luiz, de Jersey. Conhecida como a biblioteca dos "fundos antigos", ela reagrupava as coleções da casa de Sainte-Geneviève, em Paris, e do colégio de Vaugirard, bem como os fundos da faculdade de teologia de Poitiers. Em 1950 acrescentaram-se 150.000 volumes vindos da biblioteca de teologia de Enghien. Nesta mesma época tem início a redação do Dictionnaire de spiritualité, cujos autores instalam-se em Les Fontaines dando continuidade à aquisição de obras sobre a Companhia de Jesus e a espiritualidade inaciana. Em 1962, a redação da revista Les Archives de Philosophie transfere-se para o mesmo local, levando consigo uma grande parte da biblioteca filosófica de Valsprés-Le-Puy. Finalmente, em 1972, a biblioteca de Aix-en-Provence enriquece os fundos com cerca de 60.000 livros de história, literatura e lingüística.

Até os anos 70, a biblioteca atendia um grande público, mas voltava-se, com especial atenção, para estudantes e professores. A partir desta data, a formação dos jesuítas concentra-se em Paris e o antigo seminário Des Fontaines transforma-se num ativo centro de pesquisa e cultura. Seu acervo prestou-se inclusive a importantes exposições de arte, em museus e bibliotecas da França, como por exemplo, "Quatro séculos de história do livro", "Os jesuítas na América Latina", "América terra de utopias" ou "Ao encontro de Sinbad". A biblioteca, contudo, manteve-se na tranqüila cidade de Chantilly, mas teve que re-orientar suas aquisições levando em conta suas ligações com os centros de formação parisienses.

O carro chefe da biblioteca é um conjunto constituído por obras de ciências religiosas, bíblicas e teológicas. A patrística está muito bem representada por uma coleção de patrologias impressas antes do século XIX e várias edições princeps dos Pais da Igreja, latinos e gregos, assim como as obras completas de santo Hilário de Poitiers impressas em 1510 ou a edição em grego de Basílio de Cesaréia, datada de 1532. A teologia, representada por cerca de 40.000 volumes, cobre as obras dos principais teólogos, da Idade Média aos nossos dias. A série de autores escolásticos compreende, entre outros, as obras completas de Buridan ou Gilles de Roma. O setor de santas Escrituras possui várias edições da Bíblia entre as quais a poliglota, editada por Plantino. Entre outras impressas por Robert Estienne, encontra-se o Novo Testamento greco-latino que apresenta, pela primeira vez, a numeração dos versículos.

As coleções de espiritualidade cobrem as diferentes escolas espirituais, as ordens religiosas, os grandes autores e também, as peregrinações, as devoções diversas e as práticas espirituais. Pode-se consultar as Institutiones de Jean Tauler, na sua edição parisiense de 1578, a primeira edição de $A$ introdução à vida devota de São Francisco de Sales ou o Ofício à Virgem Maria composto por Nicolas Fouquet na prisão. Toda uma parte destes fundos é dedicada à pregação e aos sermonários, alguns de extrema raridade, como é o caso de Conciones breves de Perrenin Memestrier, impresso em 1633. A coleção de catecismos diocesanos (do século XVII ao XIX) tem mais de 500 obras. A espiritualidade inaciana e a história da Companhia de Jesus ocupam uma grande parte dos fundos. Encontramos, aí, livros raríssimos, como as primeiras edições dos Exercícios espirituais ou das Constituições. 
As sessões sobre ciências filosóficas são ricas de obras e estudos sobre a Antigüidade greco-latina, graças a uma bela série dos Comentários de Aristóteles impressos no início do século XVI. Podemos ler, também, autores da Idade Média, filósofos tomistas, scotistas e jesuítas consultando, igualmente, as edições originais e críticas de filósofos modernos como Descartes, Leibnitz, Kant, Hegel. Nos fundos de história da arte encontramos Arquitetura ou a Arte de bem construir de Vitrúvio, impresso em 1547, pelo editor Jacques Gazeau, bem como um alentado conjunto sobre o simbolismo na arte. As inúmeras edições de Alciat, Ripa, Ménestrier bem como de arte religiosa encantam o leitor.

A geografia reúne crônicas de viagem e de explorações como a Historia de gentibus septentrionalis, de Olavo Magno, impresso em Roma em 1555 ou a Description des royaumes de Naples et Sicile, do abade de Saint-Non, em Paris, 1781. As coleções de história contém um número considerável de memórias e crônicas feitas por testemunhas de acontecimentos. Documentos raros como a Brevíssima relacion de la destruycion de las Indias, por Las Casas, (Sevilha, 1552), a Relation de la bataille de Marengo, de Alexandre Berthier (1804) ou Ithaque, le Péloponèse, Troye, de Heinrich Schliemann, (1864) com o autógrafo em grego do autor.

A literatura grega e latina, francesa clássica e as literaturas estrangeiras representam 60.000 obras. Encontra-se, em Les Fontaines, um conjunto muito completo de tratados de gramática e retórica, bem como ricos ensaios de humanistas do Renascimento como Budé ou Erasmo.

Os periódicos ocupam um meio andar do edifício. São conservados 3.500 títulos que vão de $L ' A m i$ de la religion et du roi às Memoires de Trévoux, ou o Journal des savants, cujos primeiros números datam de 1665 até periódicos contemporâneos. Uma parte muito interessante da biblioteca abriga 200 incunábulos que incluem do Exercitorio de la vida espiritual, do cardeal Cisneros a um Diodoro de Sicília, impresso em 1559. Os fundos iconográficos são igualmente fascinantes e reúnem mais de 30.000 gravuras com temas religiosos. Documentos iconográficos referentes à Companhia de Jesus como retratos, colégios e missões, podem ser igualmente úteis para o pesquisador. Vale sublinhar a série das Conquistas do imperador Quianlang, realizada para o imperador da China por gravadores ocidentais a partir de desenhos do jesuíta Castiglioni.

A reunião de tantas obras atesta a exemplaridade com que os bibliotecários da ordem jesuíta reuniram e organizaram uma das mais ricas e importantes bibliotecas francesas. Seu horário de funcionamento é: de segunda a sexta-feira: $8 \mathrm{~h} 30$ - 12h30 - 13h30, 18h30; sábados: 8h30 - 12h30,13h30 - 17h30. A tarifa anual para estudantes é de 120 francos franceses; a consulta diária custa 20 F.F. A biblioteca conta com um aparelho xerox, um leitor de micro-fichas, um serviço de orientação e informação por correio e uma equipe de documentalistas e bibliotecários para ajudar o leitor, in loco. Seus fichários estão organizados por índice geral de autores, toposistemático, periódicos e coleções, hagiografias, biografias e teses. Seu endereço para correspondência é:

- Route de Gouvieux, B.P 219, F - 60631 Chantilly, France.

As cartas podem ser endereçadas ao Padre Tandonnet S.J, cuja amabilidade e extrema paciência fazem dos salões de leitura de Les Fontaines, um verdadeiro paraíso.

Mary Lucy Murray Del Priore Depto de História - FFLCH/USP 


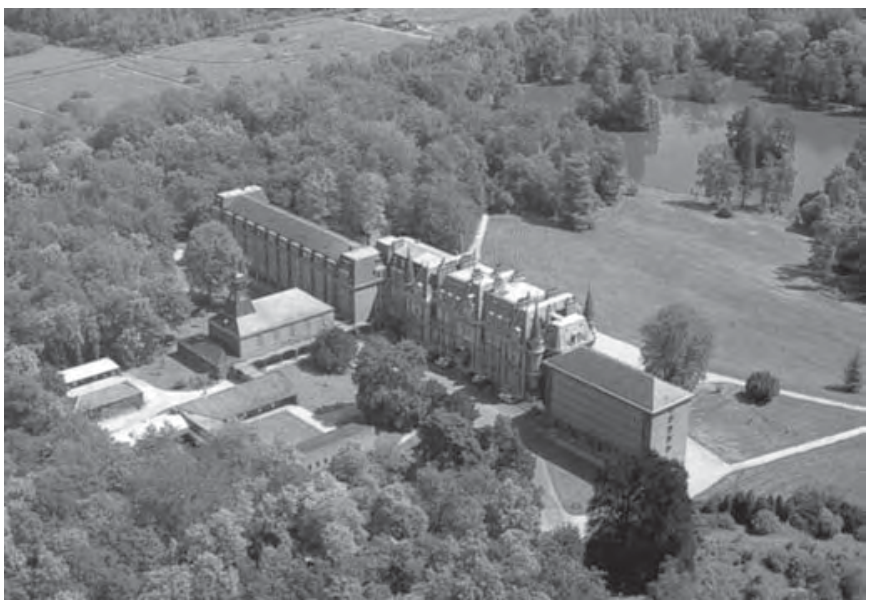

Les Fontaines - Chantilly - Foto de Marcel Chevret

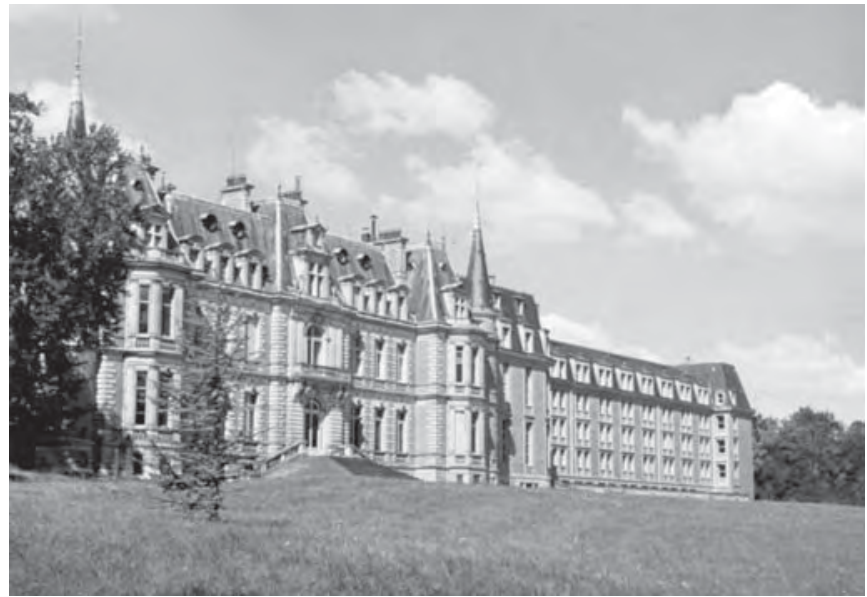

Les Fontaines - Chantilly - (Oise) 